\title{
Guidelines for Social and Economic Rehabilitation
}

\author{
PETER G. NICHOLLS (PRINCIPAL AUTHOR) \\ University of Aberdeen, Aberdeen, $U K$
}

\begin{tabular}{|c|c|c|}
\hline Chapter & Focus & Intended readership \\
\hline $\begin{array}{l}1 \text { Understanding Social and } \\
\text { Economic Rehabilitation }\end{array}$ & $\begin{array}{l}\text { Concepts, definitions and general } \\
\text { principles; operational principles; } \\
\text { how to identify an appropriate } \\
\text { programme response }\end{array}$ & $\begin{array}{l}\text { Senior managers, project leaders and } \\
\text { managers }\end{array}$ \\
\hline $\begin{array}{l}2 \text { Managing Social and Economic } \\
\text { Rehabilitation }\end{array}$ & $\begin{array}{l}\text { Organizational culture and } \\
\text { structure; the project cycle and } \\
\text { project planning; monitoring and } \\
\text { reporting; recruiting and training } \\
\text { staff }\end{array}$ & $\begin{array}{l}\text { Senior managers, project leaders and } \\
\text { managers }\end{array}$ \\
\hline $\begin{array}{l}3 \text { Managing and supporting field } \\
\text { activities }\end{array}$ & $\begin{array}{l}\text { Community relations; advocacy } \\
\text { and local associations; special } \\
\text { needs groups; vocational training } \\
\text { centres; local needs; micro-credit } \\
\text { programmes }\end{array}$ & $\begin{array}{l}\text { Project leaders and managers, senior } \\
\text { field-level staff, rehabilitation of ficers } \\
\text { and social workers }\end{array}$ \\
\hline 4 Field experience & $\begin{array}{l}\text { Transactions between field staff } \\
\text { and clients; the selection process; } \\
\text { psychological needs and skills } \\
\text { assessment; motivation, vocational } \\
\text { and other training; interventions; } \\
\text { action plans; expanding the work }\end{array}$ & As above \\
\hline 5 Assessing impact & $\begin{array}{l}\text { The role of indicators in assessing } \\
\text { change; identifying and using } \\
\text { indicators }\end{array}$ & As above \\
\hline $\begin{array}{l}6 \text { Case studies and discussion } \\
\text { material }\end{array}$ & $\begin{array}{l}\text { Case studies and discussion } \\
\text { material intended for training } \\
\text { purposes or to promote new } \\
\text { thinking }\end{array}$ & Staff at all levels \\
\hline 7 Getting started & $\begin{array}{l}\text { Practical application of the } \\
\text { guidelines and recommendations } \\
\text { for real-life scenarios }\end{array}$ & $\begin{array}{l}\text { Senior managers, project leaders and } \\
\text { managers }\end{array}$ \\
\hline $\begin{array}{l}8 \text { References, resources and } \\
\text { resource centres }\end{array}$ & $\begin{array}{l}\text { List of contributors, publications, } \\
\text { resource organizations, training } \\
\text { centres etc }\end{array}$ & $\begin{array}{l}\text { Senior managers, project leaders and } \\
\text { managers }\end{array}$ \\
\hline
\end{tabular}




\section{Introduction}

Leprosy is one of the oldest diseases of mankind and has a unique social dimension. In both eastern and western cultures, fear of the disease has existed from ancient times. In no other disease have individuals been made to leave their families and communities and forced to live as outcasts in separate colonies or settlements. For many of the men and women affected by leprosy, simply overcoming the infection is not sufficient to allow a straightforward return to their previous life-style. The World Health Organisation estimates there are some 2-3 million people worldwide with significant disability due to leprosy.

Until recently, those abandoned by their families were cared for in institutions which provided care and shelter. Since the treatment lasted for many years, they were kept in the institutions as permanent residents. They were engaged in different occupations like agriculture, animal husbandry, weaving and tailoring. Such an approach was considered 'rehabilitation'. Yet in that system, individuals became totally dependent on the institution for survival. There was no possibility of restoration or reintegration within family or community.

With the advances in treatment procedures and surgery, this institution-based 'rehabilitation' has become outdated. Through social and economic rehabilitation, people cured of leprosy are helped to regain their place in the community. Opportunities are developed to help them find productive employment, to contribute to the economy of their family and to live with dignity as useful and self-supporting members of the community. Family and community support the rehabilitation process.

Social and economic rehabilitation is a unique task. The approach may not be duplicated between places or even from one person to another. The guidelines for social and economic rehabilitation have been formulated as a response to the complexities of the work.

Through the experience and knowledge of those involved in the field, it is hoped that interested persons and institutions may recognize the elements of best practice and go on to provide a better service to those in need. The cure for leprosy remains incomplete until the people affected regain the social and economic status that allows a dignified life.

\section{How to use these guidelines}

In preparing these guidelines for Social and Economic Rehabilitation, our intention has been to provide information and advice to managers and field staff at all levels and in a wide variety of projects. The earlier sections are intended for senior managers concerned with definitions and strategic issues. The later sections will be of more interest to staff in the field. There are suggestions for group work and training sessions that will make the material accessible to the widest possible range of staff. The material presented here will also be of interest to people involved in Community Based Rehabilitation.

\section{Understanding social and economic rehabilitation (SER)}

This chapter describes the developments that led to the current interest in the rehabilitation of people affected by leprosy. There is now a clearer understanding of priorities and of 
appropriate ways to respond; three general principles are identified. The context for the work is the broader impact of leprosy. The focus must be upon the concerns of people affected by leprosy and their families and communities. The various approaches adopted by current programmes are used to demonstrate operational principles recognized as important in rehabilitation. Issues that need to be considered when developing strategic aims and objectives are identified.

The chapter is intended for the leaders of organizations considering a first involvement in SER or seeking alternative approaches in their existing work.

\subsection{UNDERSTANDING THE NEED}

Between 1989 and 1999 more than 10 million people were cured of leprosy. Multi-drug therapy (MDT) has ensured that most have avoided impairment, but there remain an estimated 2-3 million people with significant disabilities caused by leprosy. To a greater or lesser extent they have experienced the stigma associated with the disease for centuries, the fearful attempts at concealment, the trauma of increasing impairment. Although many people are resilient enough to cope with the effects of leprosy, others need help if they are to resume their previous way of life. These individuals are the focus of SER programmes.

The scope of the rehabilitation process is now better understood. In his Editorial, Dr Gopal describes the historical approach to rehabilitation. While treatments were largely ineffectual, there was little chance to restore the previous quality of life. The introduction of MDT has had a major impact on all aspects of leprosy work, including rehabilitation. It is now recognized that rehabilitation is possible, but the sheer complexity of the physical, psychological, social and economic impact of leprosy makes the task difficult. People who have relied on welfare for years may have become dependent, unaware that there is an alternative and they might return to an earlier lifestyle.

The challenge to organizations is to find an approach that is caring yet encourages people affected by leprosy to manage their own lives in the community. The attitudes of family and community are a further challenge in formulating an appropriate response. Speaking at the ILA Conference in Beijing in September 1998, Dr Arole, Director of the Jamkhed Project in India, 18 identified the principles upon which that response should be based:

A change of paradigm is needed, recognizing people as subjects, not objects, and workers as enablers and not providers. Interventions must be supportive and responsive, empowering rather than diagnostic. They must include addressing the needs and resources of the community and extending its capacity.

Dr Arole's vision of programmes that give priority to the needs and skills of individuals and are at the same time responsive to the views of the community is fundamental to successful rehabilitation and to these guidelines.

The approach to SER should therefore be based on three principles:

1. A recognition of the broad impact of leprosy on the individual; in other words, its physical, psychological, social and economic effects.

2. Responsiveness to the concerns of individuals affected by leprosy. This requires an approach that restores dignity and self-respect; in other words, participation and empowerment.

3. Sensitivity to the concerns of the families and communities affected by leprosy. Members of the family and the community have an important role to play in rehabilitation.

These principles underlie many existing SER programmes, although over the years local 
priorities may have evolved in addition. Broadly speaking, the objectives are the restoration of dignity, increased economic independence, the reduction of stigma and the achievement of integration. SER recognizes the importance of the community and the relevance of poverty. It pays attention to groups with special needs, specifically children, older people and women.

The relative weight given to these factors by different projects has resulted in the wide variety of current SER programmes. Yet most projects would agree with this concise statement of aims made by one contributor: 'To live as a useful, self-supporting member of community'. By speaking of social and economic self-reliance and adding the idea of usefulness, this phrase neatly embodies the principles of SER.

\subsection{OPERATIONAL PRINCIPLES AND PRACTICE}

The wide-ranging impact of leprosy on the individual and the social and economic differences between the communities in which it is found have led to a great diversity of rehabilitation needs. However, it has been possible to identify a number of common principles, six of which will be discussed here:

- The holistic principle

- The participatory principle

- Sustainability

- Integration

- Gender sensitivity

- Sensitivity to special needs

Elements of all six will be present in most SER programmes.

\section{The holistic principle}

As used by development workers, 'holistic' means an awareness of, and responsiveness to, every aspect of life. In these guidelines, this means a concern for the physical, psychological, social and economic well-being of people affected by leprosy. Holistic programmes include activities that address each of these aspects, and thus require teamwork by professional staff from a variety of backgrounds. SER activities may be linked to leprosy treatment, prevention of impairment and disability and leprosy control, with arrangements for cross-referral. Immediate access to newly diagnosed cases gives SER workers the chance to minimize the impact of the diagnosis and start rehabilitation at the earliest possible moment. Stigma is tackled either through local education or by advocacy work up to the national level.

Example: In one project in Ethiopia, SER work focuses on the members of self-care groups in villages. It seeks to widen their activities through functional education, and encourages the setting up of small projects that benefit members of the group and the local community.

\section{The participatory principle}

Respect for, and responsiveness to, the voice of the client is central to rehabilitation. You should give special attention to people whose self-esteem has been eroded by leprosy, actively involving them in decisions about improving their quality of life. This leads to 'empowerment': the ability of the client to make decisions and manage the transactions of everyday life. Unless clients are enabled to 'own' the process of rehabilitation, they will not 
be fully committed to it. Members of the family and the community can be involved in the process, as may associations of people affected by leprosy (8.1 lists publications on related development issues).

The participatory principle has far-reaching implications. It enables people affected by leprosy to give their own views about project activities and suggest their own outcomes; it also questions traditional assumptions. The organizational implications are discussed in 2.1 and the implications for staff recruitment and training in 2.5. Social audit may be used to assess the organization's responsiveness to clients (see 2.4)

Example: In Ethiopia, staff organized a discussion to find out what a group of women wanted to do. Four of the women decided to start a food processing business. After some early difficulties, they eventually rented a shop and employed a shopkeeper. More women have joined in since then, and now 24 of them are involved and earn a regular income.

\section{Sustainability}

This means activities that bring lasting benefit. A community-orientated approach ensures that interventions to help people affected by leprosy are acceptable to the community and benefit other people. Active support from the community may not be essential, but acceptance certainly is. Encouraging support from the client's family makes for a sustained benefit. Direct involvement of family and community members and sharing of benefits further increases sustainability. Responsiveness to environmental, seasonal and market factors is also important.

Example: A regular income can often bring respect and overcome stigma. In India, several projects work through vocational training centres and job placement, helping clients to find permanent paid employment. Where job opportunities are more restricted, some organizations provide employment in their own workshops.

\section{Integration}

Rather than creating special services for people affected by leprosy, you should use existing services provided by other organizations for the whole community. You will need to set up referral systems and negotiate access to services. You could also fill gaps in the services provided by others: for example, by providing training courses in fieldwork techniques or in leprosy awareness. This approach makes the best use of available services and resources. National plans for co-ordinating services to people with disabilities may require the integration of all leprosy-related services.

The integrated approach is particularly appropriate in situations where the proportion of people affected by leprosy is low or where health and voluntary services are well developed. It avoids the discriminatory effect of setting up services solely for one group of people and benefits from the expertise in the wider world of disability services, especially communitybased rehabilitation (CBR). Publications about CBR are listed under 'Health care' and 'Rehabilitation for people with disabilities' in 8.

Examples: In Nepal, the Release project recognizes a wide range of disabilities and works with other NGOs in the field. In Tanzania, Uganda and Egypt, government programmes and CBR are integrated in a national plan for services to people with disabilities. 


\section{Gender sensitivity}

To date, little attention has been paid to the need for a gender-sensitive approach to SER, and projects have often been biased in favour of men. In fact, leprosy can have a greater impact on women, as they are more likely to face exclusion from the family or the community. You must ensure that women enjoy equal access to services and participate actively at all stages. Gender sensitivity is also important in the recruitment and training of field staff. In general, projects should pay more attention to the circumstances of women, what they do and what they are.

Example: Workers in Tanzania recognized that leprosy had a quite different psychological impact on women than on men. They therefore improved the gender awareness and responsiveness of their work; one immediate result has been the appointment of more women staff.

\section{Sensitivity to special needs}

In addition to women, many other groups, such as children and older people, have special needs. Differences of language, culture, religion or location may be significant. You should identify these needs and the activities that can respond to them.

Example: In 3.4 there is an example that describes the needs of children affected by leprosy, identifies risk factors and suggests a programme response.

These operational principles are neither exclusive nor optional. You must consider whether they are relevant to your own priorities and to local needs.

\subsection{DEFINING THE TASK}

My education came from the people affected by leprosy themselves . . . it is still continuing.

Contributor to the guidelines This subsection describes how you can collect and analyse the information needed to prepare a statement of strategic aims and objectives.

There are five main objectives:

1. To discover the number of people affected and the level of individual need.

2. To understand the community and its needs, and to identify the physical, social and other constraints in the local situation.

3. To identify an appropriate response, taking into account any special needs.

4. To estimate the likely requirements for skills, materials and funding.

5. To secure the commitment of donors and local authorities.

You should collect information in an open-minded way, giving priority to the views of people affected by leprosy and their families and communities. Rather than relying on a simple questionnaire, use a range of different methods: for example, observation, comparison and noting the response to pictures and diagrams. For such purposes, development workers prefer to use Participatory Rural Appraisal (PRA); see 5.4.

Careful analysis of this information will provide a secure basis for planning and ensure that activities are appropriate to the local situation.

\section{Estimating the need}

The first step is to estimate the number of people who are affected by leprosy and need help with rehabilitation. Figure 1 shows how the WHO terminology can be used to describe the 


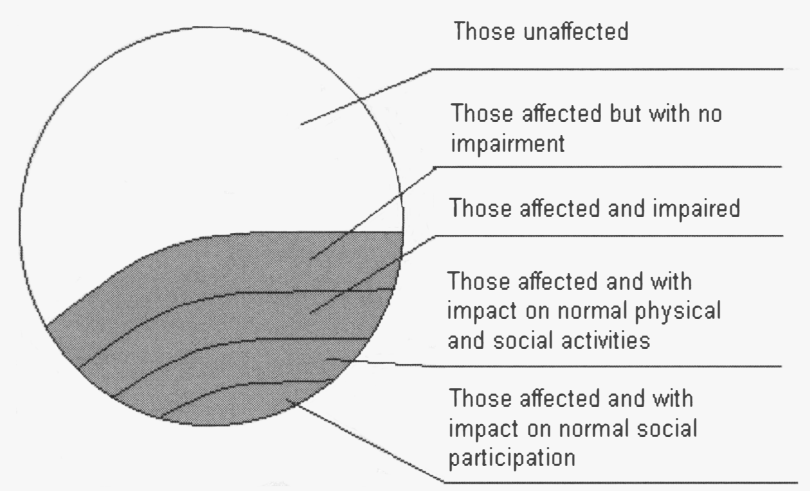

Community members affected by disease

Figure 1. The impact of leprosy.

impact of leprosy and Figure 2 shows that not everyone will need help. Dr Gopal recommends that the people affected be divided into six categories:

1. Those with no physical disability and no social or economic problem.

2. Those with physical disability but no social or economic problem.

3. Those with no physical disability but with social or economic problems.

4. Those with physical disability whose social and economic life are under threat.

Identfying those in need of SER Services

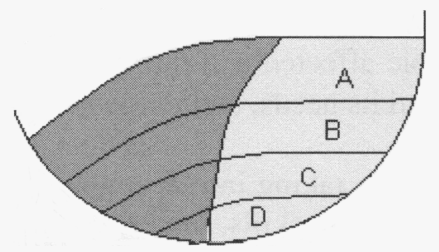

Community members affected by leprosy

Individuals in need of SER assistance

A - Individuals with no impairment but suffering from stigma

$B$ - Individuals with impairment but no restriction of normal activity or participation but suffering from stigma
C - Individuals with reduced activity, perhaps in the form of reduced earnings ability or mobility and experiencing stigma

$D$ - Individuals with reduced participation, perhaps in the form of lost earning potential, economic dependence and social exclusion

Figure 2. Those in need of SER. 
5. Those with physical disability whose social and economic life is already dislocated.

6. Those who are aged, suffering long-term dislocation and in a state of destitution.

People in categories 1 and 2 do not need help with social and economic rehabilitation. Those in category 3 may need counselling and psychological support, and will benefit indirectly from programmes that tackle stigma in the community. Those in category 4 and 5 are the primary targets of SER. You may need to concern yourself with people in category 6 and acknowledge the need for an appropriate welfare programme.

A survey of people affected by leprosy will give some indication of the numbers in each category. Choose a few individuals and talk to them about the impact of leprosy on them and the range of their needs. Use this information to help you identify priorities for the proposed programme.

\section{Community needs and physical and social constraints}

The psychological, social and economic effects of leprosy are largely determined by the community's attitudes towards the disease. These attitudes will vary from place to place, so you must talk to key local people who can outline the concerns of the community. Identify any special needs groups. Explore the significance of gender. Find out about the local terms used to describe leprosy: some may have negative connotations while others may be socially acceptable (see 3.1 and 3.2).

Physical constraints on the project will include the distribution of the local population, the nature of the physical environment, and the availability of transport and communications. These are important for access, meetings, follow-up and estimating costs.

\section{Deciding upon the response}

If there are large numbers of people affected by leprosy and no existing services, you may be justified in creating an entirely new programme. But if the numbers affected are small and/or health services or services for people with disabilities already exist, you should concentrate on filling gaps and ensuring that people affected by leprosy get access to services.

Decisions must also be taken about the level of participation. You should consider the resource implications of the holistic approach, as well as those of sustainability, gender sensitivity and special needs. The organization will also have its own priorities, preferences and experience to take into account.

\section{Skills and resources}

The most important need is for trained staff. Will it be possible to find social workers, project officers, financial controllers and managers willing to work in the area? Local staff may need to be trained; people with experience of other organizations will be particularly valuable. You should compare alternative approaches to the work in terms of the personnel, administration and finance they might need.

\section{Authorization and funding}

It is vital to find as early as possible a donor prepared to fund the proposed work. You may need to prepare case studies and outline proposals to persuade a donor to commit resources. 
Mission statement

To facilitate physical, psycho-social and economic restoration of people with disabilities or social handicap in partnership with affected people and communities.

\section{Project focus}

To provide assistance for people of all ages, races, religions or sexes with different types of disability and to work with the community to create positive attitudes, for the participation of community members in rehabilitation activities and to enable communities to assist their people with disabilities. To maximize physical abilities, to gain access to all services and opportunities available to the general population and to achieve full social integration within their communities.

Figure 3. Examples of mission statement and project focus.

At an early stage you should also seek authorization from local authorities and some indication of the availability of local funding.

\section{Statement of strategic aims and objectives}

On the basis of the information you have accumulated, you should now be able to write a statement of your strategic aims and objectives: in other words, a mission statement. In Nepal, this is a statement of principles (see Figure 3) that provides the basis for more detailed planning.

The ILA Congress in Beijing identified five objectives for organizations involved in SER. These move the focus of interventions beyond the individual towards the broader issues of rights, the role of health professionals and the effective use of resources:

1. Equality of rights for people affected by leprosy.

2. Better understanding of the need for rehabilitation.

3. More attention to psychological, social and economic rehabilitation using a holistic approach.

4. More sensitivity among health workers to the need to empower clients.

5. Improved co-ordination between organizations to make best use of scarce resources and skills.

Analysis of the local situation and preparation of a mission statement will allow you to prepare a document that will guide your further planning. The next steps are to consider in detail the implications of the work for your organization, to identify your objectives and prepare a project plan.

\subsection{SUMMARY}

\section{Understanding the need}

- Among people affected by leprosy, those unable to support their families or maintain their former standard of living will be the focus of SER activities.

- The needs of an individual may be physical, psychological, social or economic. 
- Responsiveness to the needs and skills of an individual promotes dignity.

- Responses must be sensitive to the views of family and community.

\section{Operational principles and practice}

- Six operational principles are recognized: the holistic principle, the participatory principle, sustainability, integration, gender sensitivity and sensitivity to special needs.

- The local situation and organizational constraints will determine the priority you should give to each of these principles.

\section{Defining the task}

- Assess the impact of leprosy: the number of people affected and the level of individual need.

- Find out about the community, its social and economic status and its needs.

- Understand the physical, social and other constraints on your action.

- Choose an appropriate form of response.

- Identify the needs for skills, resources, materials and funding.

- At an early stage, ensure that funding is available and your intervention is acceptable to the local authorities.

- Prepare a statement of broad aims and objectives to guide your detailed planning.

\section{Managing SER}

This chapter is concerned with the organizational implications of SER. It explains the need for an organizational culture based on listening and learning, and the implications this has for leadership and decision making. There is a discussion of planning and the procedures for monitoring and reporting. Finally, there is a subsection on staff recruitment and training.

The chapter focuses on aspects of management relating specifically to interventions in social and economic processes, and hence will be of interest to senior and project managers.

\subsection{GETTING ORGANIZED}

This subsection shows how SER requires an organizational culture that responds to information from the field and a leadership style based on delegated decision-making and teamwork.

\section{Organizational culture}

If the concerns of clients and the views of the community are to carry any weight, there must be good communication between the project, the client and the community. There should also be good communication within the organization and teamwork between staff at all levels.

For these reasons, a 'listening and learning' approach will be a recurrent theme in these guidelines. Such an approach requires a reversal of traditional management practices: managers must learn to respect the experiences of clients, field staff and other professionals. Listening must be seen as an essential way of creating understanding and generating knowledge. Learning involves a willingness to change priorities or to 


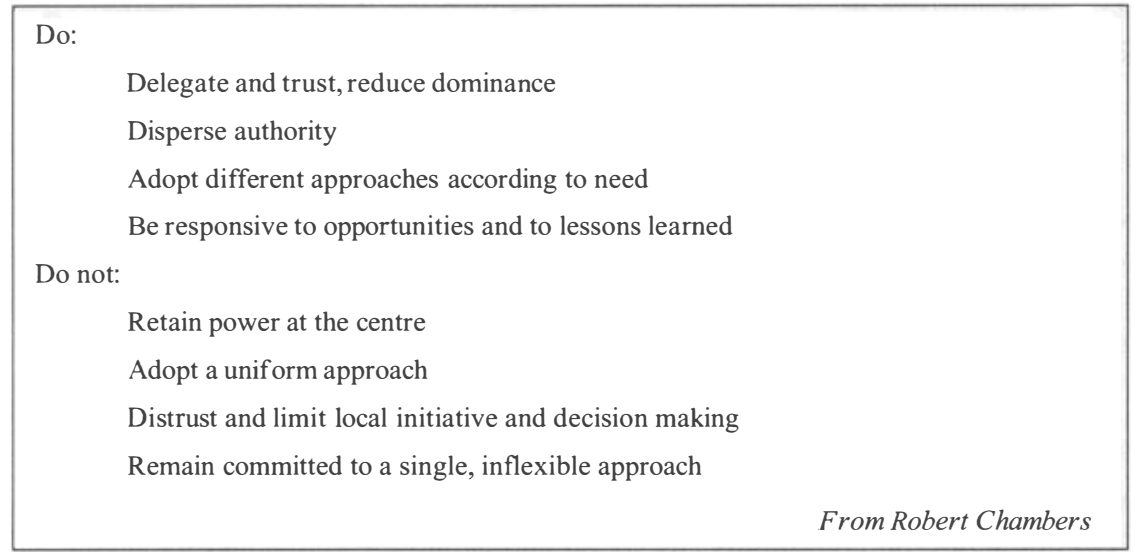

Figure 4. Reversal of priorities.

reconsider long-standing assumptions. In Figure 4 Robert Chambers summarizes aspects of management that need to be reassessed to shift the focus on to the client.

Figure 5 shows the complex flows of information that occur within the Listening and Learning approach. Such communication does not just happen: listening skills need to be developed, particularly in identifying what is important.

An organizational structure that devolves responsibility to field managers is preferable to a strongly hierarchical arrangement. Field managers and social workers monitor the progress of fieldwork, maintain relations with the community and share information with other organizations. Field assistants are directly involved in assessment and motivation, and make referrals to social workers when their help is needed. The work must be based upon mutual respect and upon supportive procedures that provide the necessary control without restricting the flexibility of response. Section 8 lists publications that discuss organizational competence and sustainability.

\section{Leadership}

Project managers must have extensive field experience and good qualifications, as these will provide the basis for effective delegation. Those who lack experience may feel threatened and retain power for themselves. A tightly controlled structure stifles initiative and responsiveness in the field. The goal should be an open management style that encourages the development of diverse skills and ideas.

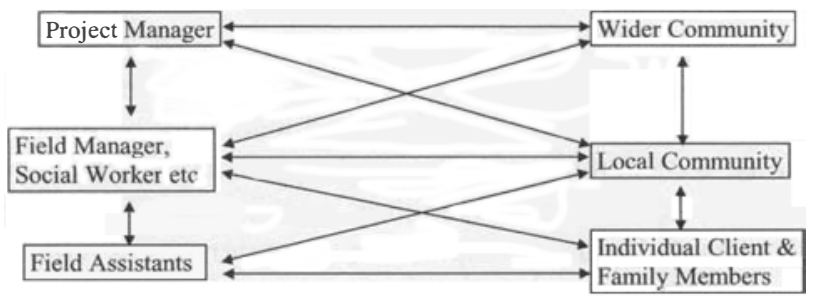

Figure 5. Channels of formal and informal communication. 


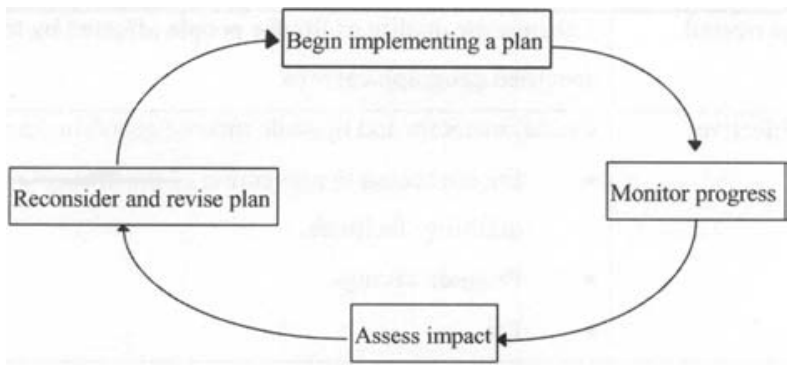

Figure 6. The project cycle.

\section{Project cycle}

Adopting a project cycle involves successive rounds of planning, implementing and reviewing which ensures that your organization responds to information from the field. A periodic review gives you the opportunity to discuss recent successes or failures and apply the lessons learned (Figure 6). This enables you to start small and build upon the approaches you find to be successful.

At field level, some organizations review the progress of individual clients at monthly intervals, others do so quarterly. Field managers may look at the effectiveness of different programme elements less frequently, perhaps once or twice a year. Rather than being seen as an 'add-on', this cyclical review process should become an integral part of project monitoring (see 2.3).

\subsection{MAKING A PLAN}

The purpose of a project plan is to provide answers to these questions

- Who is to benefit?

- What should be done?

- How is it to be done?

- When is it to be done?

In general, planning for SER is no different from planning any other programme, except for the following three complications:

- Leprosy has a complex impact on the people affected, requiring multi-disciplinary responses for each individual.

- The attitudes of the local community often mean that affected people are stigmatized (and indeed, often stigmatize themselves). Programmes should address the needs of communities as well as individuals.

- The potential for sudden physical deterioration requires close co-ordination with prevention of impairment and disability activities and careful follow-up.

Preparing a project plan involves making a clear statement of every aspect of the proposed work. This is not just to meet the requirement of donors or government-it is essential if the project is to work. A comprehensive plan provides the basic information needed to carry out staff recruitment, project activities, monitoring, reporting and evaluation.

A structured approach to planning, paying attention to detail, is preferable to an unstructured approach and donors prefer it. The methods projects can use include the Logical Framework or Goal Oriented Project Planning. 


\begin{tabular}{|c|c|}
\hline $\begin{array}{l}\text { Strategic or overall } \\
\text { objective }\end{array}$ & $\begin{array}{l}\text { Enhance the quality of life for people affected by leprosy in a } \\
\text { specified geographical area }\end{array}$ \\
\hline Specific objectives & $\begin{array}{l}\text { Create, maintain and upgrade income generating activities. } \\
\text { - } \quad \text { Ensure access to prevention of impairment and } \\
\text { disability facilities. } \\
\text { - } \quad \text { Promote savings } \\
\text { Etc. }\end{array}$ \\
\hline Strategies & $\begin{array}{l}\text { Work with organizations providing income generating and } \\
\text { CBR services. } \\
\text { - } \quad \text { Form groups and encourage savings. } \\
\text { - } \quad \text { Provide follow-up service. } \\
\text { - } \quad \text { Etc. }\end{array}$ \\
\hline Activities & $\begin{array}{l}\text { Select clients. } \\
\text { - } \quad \text { Provide loans. } \\
\text { - } \quad \text { Create database for use by clients. } \\
\text { - } \quad \text { Hold review meetings. } \\
\text { - } \quad \text { Etc. }\end{array}$ \\
\hline
\end{tabular}

Figure 7. A plan for Community Based Rehabilitation activities in Ethiopia.

It is important to understand the meaning of the technical terms used in project planning: Figure 7, which describes a CBR programme in Ethiopia, gives some examples.

The time and effort that goes into preparing a plan can give it an almost sacred status, defying all possibility of revision. But SER projects must be flexible, ready to react to the lessons learned and the opportunities that arise. Plans for such projects should therefore emphasize methodology rather than specific activities and make it clear that priorities can change in response to practical experience. Donors should be kept informed of any significant changes.

\subsection{MONITORING PROGRESS AND REPORTING}

Monitoring project activities and progress produces information that feeds the review process project cycle described in 2.1 (Figure 6). To be of any value, it must result in decisions and actions. In a well-designed system, information generated at field level should be circulated widely within the organization and also externally.

Monitoring may also be applied to internal processes, such as the selection of clients or the performance of staff. Rather than carrying out monitoring through separate Monitoring and Evaluation Units, you should make it an integral part of field activities, owned by and managed in the field.

The key questions you should ask when assessing the monitoring and reporting requirements of the project are:

- Who needs to know?

- Why do they need to know

- When do they need to know?

- How much do they need to know? 
These points are expanded below

Who needs to know? Monitoring systems are too often biased towards the needs of senior managers and donors; field staff do not always see the benefit of collecting data. So when listing the people who need information, do not forget the people within the project-project leaders, field managers and field staff_as well as those outside. Reporting to clients and advocacy organizations shows your respect for their commitment and encourages their involvement.

Why do they need to know? To be of real benefit to the project, monitoring and reporting should be designed to meet the needs of people directly involved in the field. Talk to the field staff and list the type of information they ask for. Traditionally, monitoring has focused on whether the project is carrying out the activities promised in its plan and is managing its budget properly, but you should also monitor the impact of the project on clients: for example, using the impact indicators identified in the Log Frame.

When do they need the information? For internal purposes, the reporting cycle may be monthly or quarterly. For external reporting, the cycle may be 6 monthly or annual (as in the case of ILEP B Questionnaire).

How much do they need to know? The minimum required for effective action: don't collect data for a 50-page report if a four-page report will do!

You will now need to find out where the information is and how you can gain access to it. Much of the data on activities and finance will be contained in the records kept by field staff and accountants, but information on processes such as empowerment and participation may be more difficult to collect. Chapter 5 describes how this can be done.

The information obtained through monitoring should be discussed as part of the review process, first at field level and then in summarized form by management. It should inform field staff about progress and enable them to identify successes and failures. This is essential for planning and for improving the effectiveness of the project.

On whose behalf should monitoring be carried out? In the procedures described above, the interests of the staff and the project have priority, yet the participatory approach to SER insists that the interests of the client be taken into account too. Participatory Monitoring and Evaluation meets this requirement by ensuring that clients are actively involved in the monitoring process and that their view on progress carries weight. The Most Significant Change programme described in 5.2 describes such an approach in Bangladesh.

\subsection{EXTERNAL EVALUATIONS}

At infrequent intervals - perhaps twice during the funding period-donors and others will wish to review the progress of a project and the effectiveness of the organization implementing it. These evaluations, which may involve project staff, visiting specialists and clients, are intended to serve as a learning process, with the findings shared in full with the project. The donor will be concerned about financial controls, management systems and cost effectiveness, as well as the impact of the work as set out in the Terms of Reference for the evaluation.

A monitoring and reporting procedure as described in 2.3 will provide some of the information needed for an external evaluation. It will allow the organization to demonstrate its responsiveness to lessons learnt in the field and to answer the donor's questions about impact, working relationships and the capabilities of staff.

Some organizations adopt as a strategic aim the recognition of people affected by leprosy 
as partners in their work. Social Audit is the method by which an organization assesses its progress towards this objective: it analyses the relative importance attached to the concerns of all the parties involved and assesses how far this enables the voice of the client to be heard first.

\subsection{RECRUITING AND TRAINING STAFF}

SER demands a wide range of skills from project staff. There are roles for many different professions. Formal qualifications and specialized skills are highly valued. Relevant experience is important. Yet all these will be ineffectual if the member of staff concerned does not know how to be respectful and responsive towards clients. Where staff recruitment is concerned, therefore, selection, induction and ongoing training take on particular importance.

Most organizations prefer to recruit field staff from the local community. They know the local culture and language, and have access to the community. Employing people who are themselves affected by leprosy adds an extra dimension of experience and understanding, enriching the relationship between staff and clients. Supervision can be provided by a small number of professionally-qualified staff who provide training and use their expertise to support the field staff. Irrespective of professional status, certain qualities are needed in all staff:

- Respect for and responsiveness to clients, demonstrated in a willingness to accept their participation.

- Good communication skills.

- Ability to work in a multi-disciplinary team.

- Staff with professional qualifications must be good teachers, willing to share their skills with others.

- Gender sensitivity.

- Ability to make sound decisions in a participatory environment.

These requirements are difficult to meet: many new staff start out with considerable commitment but their enthusiasm falls away as they realize the demands of the work. The following methods of support should help to prevent this:

- An induction process for all staff. This should involve several weeks of training, particularly in listening and communication skills and in the organization's values. Some recruits will drop out during the induction process as they become aware of what the work will be like. Staff may be sent for training at one of the centres listed in 8.3.

- The contents of the training should include: 'how to' information; best practice as defined by the project; gender sensitivity; sensitivity to other special needs; availability of resources, etc. Information about social work in leprosy can be found in the publications listed in 8.

- On-the-job training refreshes existing skills and adds new ones. Suitable training courses or training material may be available locally from organizations outside the leprosy sector.

- Supervision and reporting lines are needed. You should prepare work plans for each staff member and compile a procedures manual; special arrangements may be needed in remote areas where access to field staff is difficult.

- Some organizations carry out a regular performance review of each staff member and set personal goals.

- Overall responsibility for each client must lie with a nominated staff member. 


\section{Getting organized}

- Create a listening and learning organization, one in which the voice of the client is heard and respected.

- Structure the organization to allow for delegated decision.

- Adopt a leadership style that is supportive rather than restrictive, and which encourages local initiative.

- Commit yourself to a regular review of plans and be prepared to respond to lessons learned in the field.

\section{Making a plan}

- A formal plan provides the structure needed to describe every aspect of a project in detail.

- Describe objectives and desired outcomes. Identify the activities needed to bring about change. Prepare plans and budgets for each part of the project.

- Plans should emphasize the responsive nature of the work.

- Keep donors informed of significant changes.

\section{Monitoring progress and reporting}

- Keep monitoring to the minimum required to meet the need for information.

- Plan monitoring to meet specific internal information needs.

- Ensure that clients participate in monitoring.

- Use the information obtained as the basis of regular reviews, and make sure that these lead to positive action.

- Make information available in summary form for wider circulation.

\section{Recruiting and training staff}

- Appoint professionally-qualified staff to key positions.

- In the field, rely on the knowledge and skills of local people specially trained for the task.

- For staff at all levels, a respectful and responsive attitude towards clients is essential.

- Identify local training centres and materials. Be aware of the training offered at internationally recognized centres. Make sure staff receive the initial and on-the-job training they need.

\section{Managing and supporting field activities}

This chapter looks at project activities in general: that is, those not related to individual clients. You will need to tackle the problem of stigma; this may involve advocacy and the encouragement of local associations. Maintaining good relations with the community helps to create the right environment for work with clients. You should be aware of groups with special needs, such as children affected by leprosy and those in need of re-housing. The chapter discusses resources such as vocational training centres and micro-credit programmes. Project managers must also be aware of local issues — such as religious beliefs, traditional customs and attitudes to co-operative work-and their relevance to rehabilitation. 
This chapter will be of interest to staff who manage at field level as well as to senior managers.

\subsection{ADDRESSING STIGMA AND INJUSTICE}

Stigma is the chief cause of the social and economic dislocation that people affected by leprosy experience. Overcoming such stigma is an essential step towards reintegration in society. Part of the response is to increase the self-confidence of the individual (see Chapter 4). This chapter is about addressing the community's attitudes towards leprosy, particularly those of long standing. Typically, people affected by leprosy are denied access to festivals, markets, employment and the local water supply. Their children may be denied schooling and later, be forbidden to marry. This results in social exclusion and economic dislocation.

In many cases, the people affected by leprosy hold the same traditional prejudices themselves, and dread the impact of the disease on their lives. The same attitudes are evident at national level, with institutional prejudice against leprosy, the barring of access to public services and other such injustices. You will need a full understanding of the nature of stigma before you can plan a strategy to tackle it; the process of 'self-stigmatization' requires particular attention.

\section{Overcoming stigma}

Tackling stigma brings benefit to everyone affected by leprosy, whatever their level of impairment, activity or participation. At the local level, you should concentrate on overcoming the ignorance and prejudice that underlie stigma. This can be done by running education campaigns targeted at key individuals or at the whole community. Activities may include exhibitions, leafleting and drama, taking place at local markets, public meeting places, health centres and schools.

Attitudes will also change if the community is involved in helping a person affected by leprosy (Figure 8). The involvement of professional people with a client can have a similar effect. Activities may be aimed at improving the knowledge of health professionals. Many projects organize special events each year to mark World Leprosy Day.

\section{Advocacy}

Many projects get involved in publicising the injustices experienced by people affected by leprosy and in working for their rights. You can use the available media and form links with

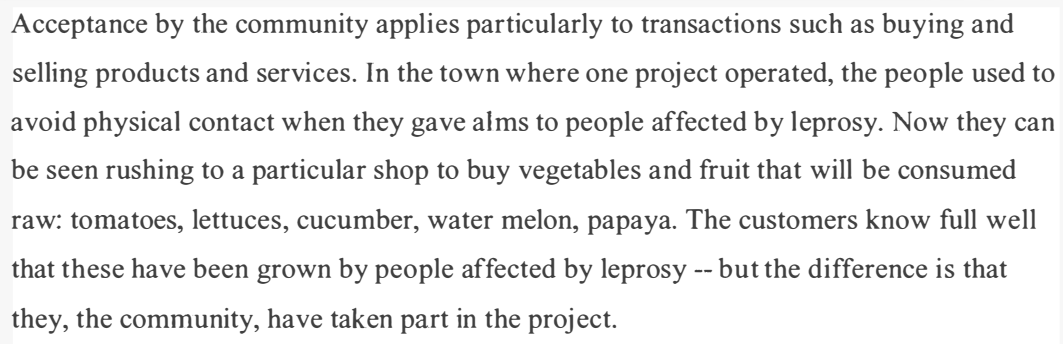

Figure 8. Involving the community: a case study from Ethiopia. 
local or national organizations concerned with leprosy and other disabilities. Bringing together people affected by leprosy into small groups or more formal associations has many benefits:

- It provides an opportunity to share experiences, develop new attitudes and acquire new life skills.

- It creates a public voice for the rehabilitation process and encourages participation.

- It develops confidence as individuals 'go public' about the impact of leprosy.

- It provides a powerful voice when confronting officialdom.

Such groups are most effective when the initiative comes from people affected by leprosy and when they reflect special needs: for example, women's associations.

Because of their differing perspectives, there is some potential for tension between such groups and the local project. But there is also the potential for beneficial partnership. The groups may be given training in leadership and money management, and encouraged to assume responsibility for advocacy. In some countries, groups extend membership to people with other forms of disability. Several countries have national organizations or co-ordinators for associations of people affected by leprosy or by other forms of disability.

\subsection{THE IMPORTANCE OF COMMUNITY RELATIONS}

If you can gain the respect of the community and maintain links with its members, they are more likely to accept your project's interventions.

In these guidelines, the term 'community' refers to households in the neighbourhood of the client that share access to a common resource (such as a water supply) or form part of a recognized unit such as a village. These communities and the client's family provide the context for all dealings between the project and the client (Figure 9). In some cases the client's family, workplace or religious centre (such as a church or a mosque) has an important role to play in rehabilitation.

For this reason, the project must maintain communication at various levels and encourage the maximum family and community support for the rehabilitation process. Even a small amount of community involvement will benefit the client. The project also benefits because it gains access to local knowledge and resources not otherwise available.

You should engage in three specific activities in the community:

1. Learn

- Find out about the community, its knowledge, skills and experience. In particular, try to understand attitudes to change: conservatism, fatalism, traditional beliefs.
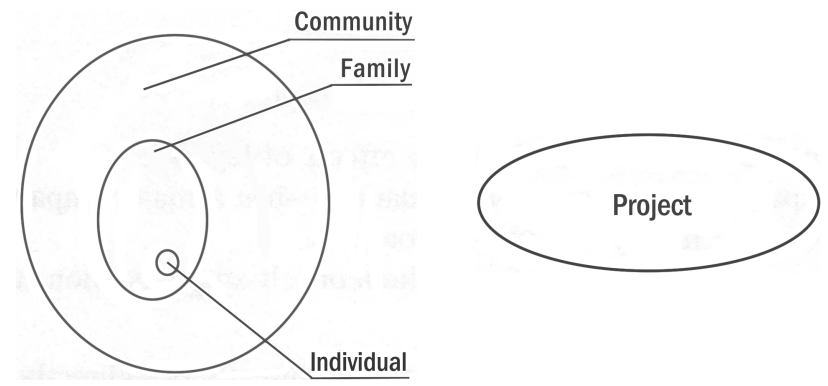

Figure 9. Communications between project, client and community. 
- Identify key people - opinion-formers, teachers, religious leaders-within the community and draw upon their knowledge. Ask them about the best ways to reach the community.

- Listen to the voice of the whole community, not just that of its leaders.

- Invite suggestions from the community.

- Monitor changes in public attitudes towards leprosy and the project.

2. Publicise

- Work to increase public awareness of leprosy, emphasizing the importance of reintegration into the community for people affected by the disease.

- Enlist support for self-help or self-care activities.

- Encourage communities to let clients take responsibility rather than set out to 'do things' for them.

3. Involve

- Involve members of the community in interventions - this ensures that solutions are acceptable and individuals are not excessively empowered.

- Even if they are not directly supporting your project, keep community leaders and other important local people informed about it.

- Maintain links with development activities that are addressing the needs of the whole community.

Maintaining good relations with the community is therefore a priority for field managers (see Figure 4). A two-way flow of information demonstrates that the project respects the community and its leaders. Regular public meetings or the distribution of written reports are ways of acknowledging the community's support.

Community Based Rehabilitation (CBR) addresses the needs of people with disabilities in the setting of their communities, and SER projects should recognize it as a potential source of expertise and resources.

\subsection{RESPONDING TO SPECIAL NEEDS}

From time to time you will need to help groups of people with special needs. Older people may be particularly at risk. Those with no land or limited resources will be the most vulnerable to seasonal changes and the availability of work. Others may have specials needs for improved housing or for resettlement. Others with special needs may include women or the residents of a leprosy colony. This subsection describes a typical response to a group with special needs, using children as an example.

The response consists of three steps:

- Identify specific needs.

- Identify risk factors.

- Identify the principles that must underlie your response.

Children are particularly vulnerable to the effects of leprosy:

- The loss of a parent—-temporary or permanent—has a major impact on a child's life style, role within the family and future prospects.

- Terminated friendships, exclusion from school or self-stigmatization can have a powerful psychological effect.

Needs will vary according to whether the child is directly or indirectly affected. Those at greatest risk include children who: 
- Are from the poorest families.

- Have lost one or both parents, or are adopted.

- Are in institutions.

- Have had only limited education.

Plan your response to the special needs of children by:

- Finding out about the significance of children in the community. What is the public attitude towards them?

- Choosing an agreed national or local standard for your intervention: for example, the International Convention on the Rights of the Child or local conventions towards the family and adoption.

- Considering the urgency of the need and the likely effect of delay.

- Finding out which special skills will be required: for example, experience in working with children

- Obtaining access to the people and institutions that will enable you to meet the need: for example, community leaders, schools.

Since children provide future security for parents and elderly relations their needs are a high priority recognized in many cultures. Similar recognition should extend to the special needs of women.

\section{Long-term needs}

A variety of different approaches have been adopted to meet the special needs of people with chronic problems relating to leprosy:

- In Nepal, groups of two or three families have been resettled together to provide mutual support. Providing assistance with housing is a common element of many programmes.

- Faced with individuals who have severe disabilities and cannot work, some projects have shifted their attention to the next generations. They have found local schools for the children and provided vocational training for family members able to work. This focus on the family is a useful way of helping those least able to help themselves.

- People who have major disabilities and no family support may require permanent sheltered accommodation or continuing care. This must be seen as the most desirable outcome, although it is sometimes difficult to distinguish between those who really do need continuing care and those who have the potential to support themselves.

\subsection{PROVIDING VOCATIONAL TRAINING}

Many people affected by leprosy live in extreme poverty and have few opportunities to earn income. Some projects therefore focus on meeting these financial needs by setting up vocational training centres. This has been effective in situations where a regular income is sufficient to overcome stigma and enables an individual to be accepted by the community (the same is true of people whose disabilities have other causes than leprosy).

Access to vocational training and the availability of secure employment are clearly vital to the success of SER. Programme responses include:

- Running a training centre and integral production unit.

- Running a training centre delivering courses that meet local employment opportunities.

- Placing clients for training by the project or outside.

- Placing clients for outside training only 
Where there are local training programmes or apprenticeships available the emphasis should be on vocational assessment and placement rather than offering training within the project. The number of clients and the existence of local courses will influence your choice of approach.

If you are proposing to set up a new centre, you should not underestimate the demands it will make upon your project and how dependent it could make you upon continuing funding. Vocational training centres require specialized skills to identify and prepare training courses and select trainees. There are issues of purchasing raw materials and marketing products. The local market needs to be closely monitored to ensure that training keeps up with changes in design, production techniques and raw materials. Financial management experience and strong entrepreneurial skills are essential. If the centre focuses upon training and there is little income from sales, it will need continuing funding.

Here are some other important points about vocational training:

- Selection for the centres is usually based upon referrals from local health service providers and may include people affected by other forms of disability. It is assumed that those making the referral will have carried out a vocational assessment.

- A quota system may be used to ensure that people from the wider community have access to the centres.

- Continuing follow-up is vital for success. Support may be provided in the form of loans to buy a house or start a small business. Other members of the family are also a potential source of support.

- The most usual way of assessing the effectiveness of centres is to report the percentage of graduates in settled employment after 1 year. Reputation and recognition of training are other indicators.

- Questions of access and the rights of clients may arise: for example, the issuing of driving licences to people affected by leprosy.

- Centres show a strong preference for local markets, thus avoiding the complexities of export or the need to respond to changes in materials, design or production in distant and poorly understood markets.

- The minimum age of trainees and the completion of their education are important points of good practice.

- Environment, safety, living conditions and security are also important issues, especially for young people.

- Centres provide training in life skills and money management; trainees are encouraged to open savings accounts.

Where clients are provided with work, it is common practice to give them loans for tools and raw materials or to improve their housing. These 'micro-credit' schemes are discussed in 3.5 .

\subsection{PROVIDING LOANS}

Since supporting clients so often requires financial outlay, many projects provide loans through a micro-credit scheme: for example, a group may receive a loan to start a goat-rearing project, or an individual starting a small business may be lent the working capital. Although loans of this kind may already be available from local banks or development agencies, they may involve an interest charge or a service charge. Projects are keen to 'revolve' their funds: 
they encourage borrowers to repay as quickly as possible so that the money can be made available to others.

Although it is common for SER projects to run their own micro-credit schemes, you should not set one up without first considering the implications. Managing a scheme is a demanding task that involves the detailed screening of applications, strict procedures, careful decision-making and the tracking of multiple financial transactions. Reporting requirements are complex. Some specific issues arise:

- Is micro-finance always appropriate? How much debt do applicants already have, and will they be able to repay? There may be better ways to address the financial needs of the poorest people.

- Do existing loan schemes charge a fair rate of interest? Do people affected by leprosy have access to them? What would be the impact of a new scheme or lower interest rates on other loan schemes in the area?

- Can the project handle the scheme? Are there legal restrictions? Does it have the management and financial skills? You should explore the past history of such schemes in the area.

- Is it possible to take a participatory approach towards loans, so ensuring 'ownership'? You can do this if you involve clients in decision making and monitoring.

- Decision making should be sensitive to gender issues and the special needs of other groups, ensuring equal access.

You must decide questions concerning the size of loans, the handling and distributing of funds, the rate of repayment, the encouragement of savings, the role of groups and cooperatives, etc, by reference to best local practice. The subject is discussed in more detail in publications by Oxfam and Intermediate Technology (see 8).

Where funding for loans is limited, assessing the potential impact will enable you to decide between applicants (see Example 2 in 5.4).

\subsection{LOCAL ISSUES}

In addition to the general themes discussed above, you will need to be aware of specific local issues that may affect rehabilitation.

\section{Urban/rural differences}

Where a project covers both urban and rural areas, there may be significant variations in community structures and attitudes to change. Your work must be responsive to local circumstances, particularly where the prioritization of needs and the perceptions of risk are concerned.

\section{Groups or individuals?}

In some countries there is general acceptance of the co-operative or group approach to rehabilitation. Elsewhere, experience with groups has been disappointing and the focus is on individuals; however, as programme benefits have gradually been recognized, so levels of participation have increased and the group approach has become more acceptable. The cyclical review process provides an opportunity to compare alternative approaches at each stage of a project. 


\section{Religion}

Researchers have identified differences between religious groups in their attitude to leprosy. The strength of traditional beliefs in an area, or the openness to new ideas, will affect the rehabilitation process.

\subsection{SUMMARY}

\section{Addressing stigma and injustice}

- Take time to understand the significance and scope of stigma.

- Tackle the problem of stigma in the local community.

- At the national level, target health professionals and engage in advocacy.

- Encourage the formation of advocacy organizations or similar special needs groups.

- Provide training in leadership and money management.

\section{Community relations}

- Learn from the community.

- Raise public awareness.

- Involve the community.

- Keep the community informed of progress and aware of how important its contribution has been.

Responding to special needs

- Identify specific needs.

- Identify the risk factors.

- Base your response upon recognized principles.

- Be aware of the special needs of children and women.

- Note that some clients will need continuing care.

\section{Vocational training centres}

- Only set up a training centre if appropriate training is not available locally.

- Consider the management implications carefully.

- Set a referral system that includes vocational assessments.

\section{Providing a loan scheme}

- Carefully consider the management and legal implications.

- Set up detailed procedures to ensure accountability.

- Ensure equal access through participation in decision making.

Local issues

- Be prepared to tailor your approach to the needs of each community.

- Consider the advantages and disadvantages of working with groups or with individuals. Start by following established local practice.

- Recognize the significance of different religious groupings. 


\section{Field experience}

This chapter looks at the activities at the heart of the rehabilitation process: the transactions between field staff and clients.

The first step is to identify the people who need help with rehabilitation. An initial assessment will provide the basis for setting rehabilitation goals agreed with the client. This is followed by a process of further assessment, motivation and intervention which builds confidence and adds new life skills. It is supported by follow-up and terminates when the agreed goals are met.

Reviewing the effectiveness of this process is an important learning exercise for the project, enabling it to make best use of its time and to extend its services to yet more clients, with the possibility of developing future group-based activities. In this chapter, experience from the field is summarized in a series of principles and action points.

\subsection{SCREENING AND INITIAL ASSESSMENT}

For each client, rehabilitation starts with screening and initial assessment. Although some projects may have the resources to accept every potential client who applies, most will give priority to those in most need or at most risk. Questions of motivation, basic skills, local priorities, community sensitivity and gender may all be relevant to the screening process. In Colombia clients are classified as :

- Willing and able to participate.

- Willing but not able to participate.

- Able but not willing to participate.

- Not able and not willing to participate.

Another, more participatory way of screening is to ask the potential clients themselves to decide which of their number is in most need and who should benefit first. This approach may avoid conflict and lead to wider acceptance of the selection process.

The initial assessment (Figure 10), will involve social workers or field staff and provide basic information about the client and the impact of leprosy. For cases undergoing treatment the process should include staff responsible for MDT and prevention of impairment and disability activities and result in a comprehensive plan of action for the client. The plan must be agreed between staff and client and allocate responsibilities.

Example: In Pakistan, assessments are followed by the formulating of a plan of action for each client which identifies the services that will be required and their intended outcomes. It describes the responsibilities of each staff member and of the client, and identifies the indicators that will reflect change. Objectives for an individual are stated using terms such as:

- Restore self-esteem and dignity.

- Increase decision-making capability.

- Enable them to provide their families with all basic needs.

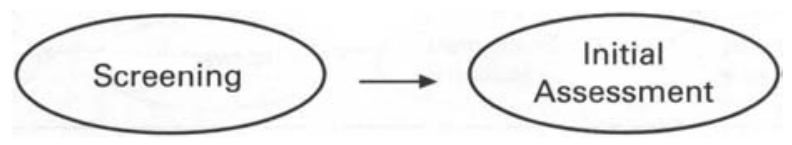

Figure 10. Screening and initial assessment. 
A. Personal, financial and social status before the disease

1. Age, marital status, education and other personal details.

2. Social status, relationships with family and community, involvement in community functions and activities, etc, before the disease.

3. Financial status, including employment history, earnings, assets and liabilities before the disease.

4. Financial status of family members.

B. Impact of leprosy and current state

1. History of the disease.

2. Social impact of the disease.

3. Psychological impact of the disease.

4. Employment and economic impact of the disease.

Figure 11. Outline for an initial assessment form.

It is essential for staff to keep a record of each contact with a client. Assessment forms may be used to record the changes caused by leprosy (Figure 11). These will form the first entry in a record system that will be updated after each meeting or transaction involving the client.

\subsection{RESPONDING TO THE CLIENT}

Real practical experience comes from the contact with the individual, bearing in mind that he/she is a human being with special needs and suffering from many internal conflicts because of the disease.

Contributor from Egypt The ultimate goal of rehabilitation is to enable people affected by leprosy to become selfsupporting and live a life of dignity in their community. Central to this process is developing a shared understanding of the needs and skills of each individual and their motivation to change. For some clients, this is a simple process. Others may need successive rounds of assessment, motivation and intervention before they acquire the necessary skills and confidence (Figure 12).

Rather than being just a convenient way to manage rehabilitation, this process of repetition is particularly important for staff. Staff contribute most effectively when they fully understand the needs and skills of the client. It is therefore essential that they share in the learning process. The cyclical approach enables them to increase their understanding and give appropriate guidance to the client at each stage.

At as early a stage as possible, you must try to understand the impact of leprosy on the life

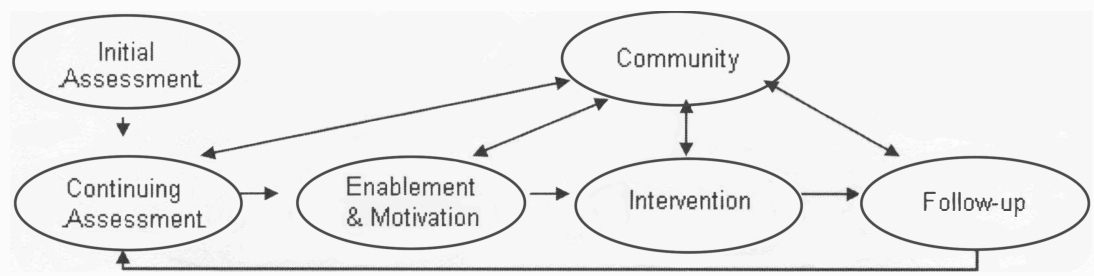

Figure 12. The process of repeated assessment, motivation and intervention. 
of the client. This will allow them to talk about the changes in their lives-something that they perhaps have never been able to do before. It helps them to come to terms with the past and prepares them to face the future. These assessments also provide staff with the background information they will need for later, in-depth discussions. Observations from the field, plus the lessons from past interventions, also contribute to the process. Communication with, and support from, the family and the community is vital; some projects encourage this by carrying out assessments in clients' homes. Subsection 4.3 looks at the assessment process in more detail.

Empowering and motivating grow naturally out of assessment; they are simply a change of emphasis. Assessment looks at the past, whereas empowerment and motivation look at what may be achieved in the future. The focus is on activities designed to create selfawareness and confidence, provide new experiences and develop a positive attitude towards change. One contributor to the guidelines described this as:

The process of finding a voice, of developing an understanding, of expressing a need. It addresses the issue of self-esteem and promotes self-confidence. It promotes responsiveness and aims for independence and empowerment. It requires a strong community-orientated approach.

Typically, when projects begin work with clients they are faced with people who have had the confidence to come forward but may have mistaken expectations of what the project can offer. This may lead to a period of confrontation and negotiation, as each party presents their own point of view and begins to understand the other's. Some clients are either not prepared to take risks or lack the support they would need to do so, and so reject any suggestions that fall beyond their experience or 'comfort zone'. Some will become open to change when they see positive change in others. As relationships develop and understanding grows, a supportive environment is created that can empower individuals to take risks and participate in activities to address specific needs (see 4.4). Throughout, the opportunity to learn from people who have already successfully completed the process is a strong motivation.

Personal commitment to an agreed intervention marks a further step in rehabilitation. These interventions may address economic or social needs, and they may involve the family or the community. They are a collaboration between client and field staff, both of whom participate in identifying the problem and seeking solutions. They require the full commitment and ownership of the client (see 4.4).

Follow-up by field staff provides support to the client throughout the process. Their observations and reports are fed back into a further round of assessment, motivation and intervention.

Over time, therefore, there may be a series of interventions with each client. Each successive intervention may increase in complexity as it tackles different needs and develops new skills. Finally, an agreement will be reached that the client requires no further help from the project and he or she will be discharged, providing staff with the opportunity to review and learn from the experience (Figure 13). If clients need continuing support, perhaps to settle into a new community or a new job, staff can provide follow-up.

\section{Scaling-up}

In addition to assessing the effectiveness of the various activities carried out with the client, the review should pay special attention to time management. Making the best use of resources is important for organizations that are new to the work and still developing their 


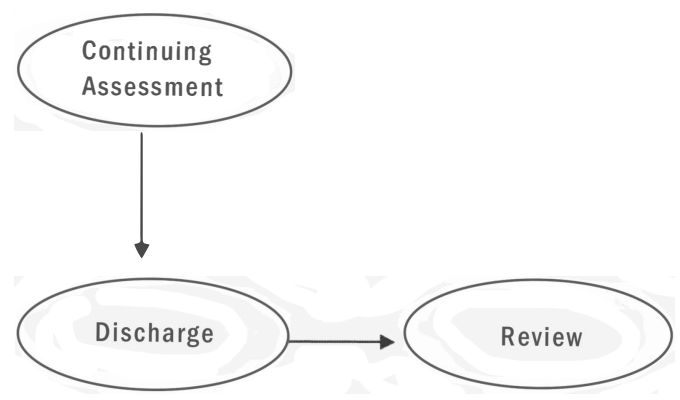

Figure 13. Discharge and review.

understanding of it. The review process enables them to identify factors that can speed up the process and reduce costs:

- It identifies specific skills in which staff can be trained to ensure more effective field work.

- A demonstration that enthusiasm is as important as good training.

- Moving away from a role that involves working for the people to one that involves working with the people.

- The identification of improved procedures based on a growing understanding.

- Reporting progress to local associations, advocacy organizations or members of the community increases public awareness. This makes the task of motivation and empowerment less onerous, as potential clients can see the benefits reaped by others.

- As larger numbers become involved, so training and other activities can focus on groups rather than individuals.

Some organizations extend the use of assessment forms to describing the impact of project activities on each client and the responsiveness of the organization. This process is closely related to the social audit approach discussed in 2.4 .

\subsection{ASSESSING NEEDS AND SKILLS}

Our lives were such that we could have quietly disappeared from the earth without anyone knowing it.

Assessing the needs and skills of clients is a key aspect of rehabilitation. It provides information about the impact of leprosy and helps clients to come to terms with the changes in their lives. The responsibility for assessment generally lies with field staff, although they will have access to professional staff through a referral arrangement. However, staff at all levels are involved in sharing the learning. This subsection summarizes the factors that bring success when carrying out assessments.

\section{The impact of leprosy}

To understand the impact of leprosy, you must first understand the client's normal life-style in the community, which will provide a basis for comparisons with his or her present state. To the outsider, 'normal' life may appear uncomplicated, but the reality may be very different (Figure 14). Understanding what has changed is an essential part of assessment and defines the nature of the rehabilitation process. 


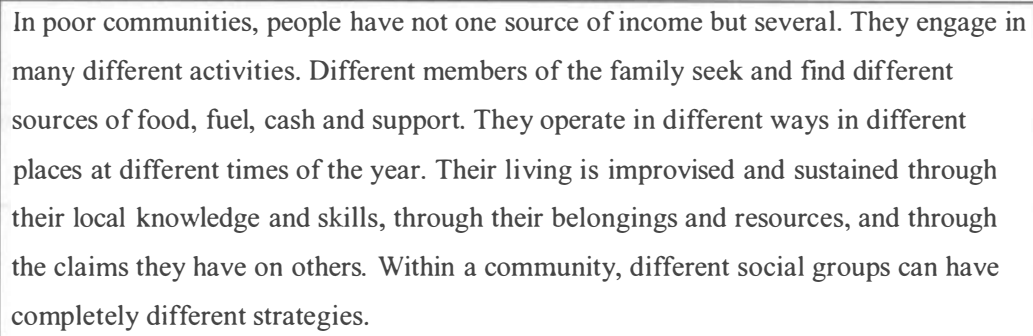

From Robert Chambers

Figure 14. 'Normal' lifestyle.

\section{Assessing self-confidence and psychological state}

It is important to be aware of the psychological impact of leprosy, which can take the form of lost self-confidence, reduced self-esteem, fear and anxiety. In most countries there is no access to professional psychologists but staff can use a few simple questions to gain some awareness of psychological needs. This should be done at the earliest possible opportunity after diagnosis. In Colombia there are referral systems in hospitals so that newly-diagnosed individuals can benefit from early assessment.

Example: Staff in Nepal assess a client's self-esteem by listening out for statements such as the following:

- I can't do anything

- I'm unable to make decisions

- No one listens to what I say

- No one treats me like a person

- I don't want to be rejected again so I don't make relationships.

Staff must learn what to listen for and how to encourage clients or their relatives to give full expression to what they are thinking. Mutual trust and respect, and the integrity of the field staff are vital for this process. Section 8 lists publications describing other social work skills. Other aspects of the work include:

- Specialist staff may be consulted: for example, to comment on physical well-being, the risk of further impairment or disability and other special needs.

- The views of members of the family and the local community should be taken into account.

- The assessment should be on-going (a meeting every month, for example) and responsive to changes that occur.

- $t$ must pay attention to detail. For example, when exploring the involvement of family members, staff should try to differentiate between mere tolerance and genuine participation. This will require them to ask 'open' questions that encourage an extended answer rather than 'closed' questions that invite a simple yes or no.

As discussed earlier, staff will collect the basic information about clients at the initial assessment. They now need to use their interviewing techniques and listening skills to understand the client's situation in greater detail. The process involves continuing assessments and depends upon informality and openness. Figure 15 is a suggested form for recording information at each session. 


\begin{tabular}{|c|c|c|c|c|c|c|}
\hline $\begin{array}{r}\text { Client's Name } \\
\text { Addre }\end{array}$ & & & & & & \\
\hline Meeting date & Participants & $\begin{array}{l}\text { Subjects } \\
\text { discussed }\end{array}$ & $\begin{array}{l}\text { Agreed } \\
\text { actions }\end{array}$ & Action by & $\begin{array}{l}\text { Checked } \\
\text { by }\end{array}$ & $\begin{array}{l}\text { Follow-up } \\
\text { date }\end{array}$ \\
\hline
\end{tabular}

Figure 15. The elements of a form to record contacts with clients.

\subsection{EMPOWERING AND MOTIVATING}

To get rid of the social stigma we have to have self-confidence first.

Cheng Li Wang, China

Empowerment aims to raise the self-esteem of clients and extend their basic life skills. It changes attitudes so that clients become motivated to change. The key activities for empowerment are increasing the client's awareness through formal and informal education and giving support and encouragement. These will be achieved through the joint efforts of the client and the project staff. Evidence of positive change in other people is also a great motivator: 'It's not just talk, then' is a typical reaction. Restored self-confidence is a major step towards overcoming stigma.

'Awareness' is the level of understanding an individual has of himself, his situation and the society in which he lives. Increasing awareness involves developing new understanding and helping the client to recognize opportunities for change. Contributors summarize their approach as follows:

- Focus on the whole person. Aim to increase self-confidence and develop basic life skills. Encourage self-expression and physical activity. Use informal methods such as drama and music.

- Respond to the fears of clients. Address the specific risk factors. Explore the underlying issues and explain the social and psychological processes at work. To do this, staff need high levels of awareness and good analytical skill; this has implications for training (see 2.5).

- Where clients have formed groups they provide mutual support amongst themselves. This can address emotional needs, self-confidence and self-care to prevent disabilities

- If clients seem to exaggerate their needs, respond with caution and try to develop a better understanding.

\section{Knowledge and skills}

Take every opportunity to increase the knowledge of clients:

- Try a variety of approaches, formal and informal, group or individual, in order to identify the most effective way to spread knowledge.

- Improve numeracy and literacy through formal education.

- Provide training that will enable the client to participate effectively in group or family activities. A wide range of subjects may be relevant: local attitudes and beliefs, health and nutrition, local agriculture, civil rights and the development of women. Local development organizations may already have courses tailored to local situations.

- Plan a training syllabus that covers a different theme each month; this enables you to give training in a variety of situations and using a variety of methods. 
- Provide training that will enable clients to make good use of a loan and manage their personal or family expenditure more effectively.

\section{Support}

This should involve field staff, family and community:

- Be responsive to the growing understanding and initiative shown by the client.

- To encourage positive attitudes and the acceptance of new ideas, share with the client the experiences of other people.

- Involve the family and community in activities.

- Give clients a second chance. If they drop out of the programme but later ask to return, allow them to do so; they will have learned from their experience. The incident should also prompt the organization to think about why the client dropped out in the first place, and whether they should have done anything differently.

Alongside the empowerment of clients, there should also be an empowerment of the staff, the organization and the community:

- Empowering staff. Staff who have inappropriate attitudes towards their work or who operate within a rigidly hierarchical structure will not be able to respond to the initiatives of their clients (see 2.1). The implications of this for recruitment and training are discussed in 2.5 .

- Empowering the community. The importance of community relations and community involvement are discussed in 3.2.

- Empowering the organization. Work schedules should allow for an adequate response to each individual. Providing staff with effective procedures, a referral system, careful supervision and on-the-job training will give them the skills and support they need to work to a timetable. Staff must know how much time is appropriate for specific tasks and be able to call for assistance when extra resources are needed (see 2.1).

\subsection{INTERVENING}

Poverty is a lack of opportunity, not a lack of ability.

Contributor from Ethiopia

This subsection discusses the importance of choosing your intervention carefully and securing the client's full commitment to it. The involvement of the community is one of several factors that will affect the sustainability of the intervention.

Interventions can only start when clients understand their own needs and have found a solution to which they are prepared to commit themselves. The level of disability, existing skills and past work experience of clients will all have some bearing on the success of the intervention, but it is their ownership of the process that will be critical.

Contributors made the following recommendations:

- The client must show initiative and motivation. Encourage decision making and commitment. A positive response from staff increases confidence. You must take the time to consider proposals in detail.

- Recognize that clients may choose an intervention for reasons that are not shared by field staff. Work to develop mutual understanding. 
- The client's ownership of the intervention is of primary importance, but field staff have an important role to play in advising and encouraging. Project managers should identify a level of involvement that allows the process to be controlled without restricting its effects or making clients feel they are 'obeying orders'.

- Accommodating the opinions of family and community encourages their members to act as guarantors and reinforces the commitment of the client.

- Every detail and implication of the intervention must be understood and accepted.

- Each intervention needs an action plan specifying outcomes. This should have the status of a contract, listing the responsibilities of the client and the other parties involved and identifying a schedule of activities. Where a small business is being proposed, a business plan will be needed.

\section{Sustainability}

The intervention must also be sustainable:

- Use the services of specialists in income generation.

- Use market surveys to assess supply and demand. Seasonal variations may affect production and earnings. Try to avoid undermining the livelihood of other people in the community .

- Vocational assessment establishes the skills and work experience of the client and takes account of the extent of disability; it then identifies potential employment and the training required. The skills of the other people involved should also be taken into account in proposals for job creation or placement.

- Aim to build on the existing skills, experience and knowledge of the client. Avoid work that is completely new.

- Work with known technology

- Provide training in how to monitor and assess progress.

- Arrange for continuous and frequent follow-up, including field visits, home visits and continued contact by social workers

- Review progress and assess the reasons for success or failure. Keep a record of each intervention and learn from it.

\section{Community attitudes}

The attitude of the local community is critical to the success of an intervention:

- The local community must be aware of what is being proposed. Its active support may not be needed, but its acceptance will encourage the client.

- Do not provide the client with benefits beyond what is acceptable to the community.

- Extend the proposed benefits to other people in need in the community.

\section{Economic needs}

Specific activities address economic needs:

- Encourage saving. Help the client to open a savings account.

- In India and elsewhere, clients may need help to apply for government support for people with disabilities: for example, funds for housing or pensions. 
- Provide pre-vocational training that will prepare the client for work. Pay attention to issues such as the risk of new disability, business skills, and informal training in the market.

- Set up a referral system to centres offering vocational training, as this will allow you to make appropriate arrangements for each client.

- If there are opportunities for local employment but no suitable training is available, think about setting up a vocational training centre (see 3.4).

\subsection{SUMMARY}

\section{Screening and initial assessment}

- Where necessary, screening should be based on project policies and local priorities.

- Initial assessments provide an opportunity to draw up an action plan for each client.

- The information collected provides the basis for assessing future change.

\section{Responding to the client}

- The repeated process of assessment, motivation and intervention builds the self-esteem and skills of clients.

- Successive interventions encourage clients to assume greater responsibility until they can manage the activities themselves.

- Information from the field feeds back into successive rounds of assessment.

- Projects should give continuing support through a follow-up programme.

- Discharging clients from the programme gives an opportunity to review the performance of the project and apply the lessons learned.

\section{Assessing needs and skills}

- Use a needs assessment form as the starting point for collecting information about the impact of leprosy on the client, but encourage open discussion.

- Develop listening skills and encourage clients to express their views

- Involve members of the family and the community.

- Work towards a shared understanding of need.

- Consult specialists when necessary.

\section{Empowering and motivating: summary}

- Raise the client's awareness by increasing their understanding of the situation and helping them to recognize opportunities for change.

- Take every opportunity to add to the knowledge of clients through formal and informal education.

- Encouragement from field staff and support from family and community will enhance motivation and empowerment.

- The appropriate organizational culture and procedures will further enhance motivation and empowerment. 


\section{Intervening}

- The client must own and be responsible for the intervention.

- The family or the community may provide support and reinforce the commitment of the client.

- Develop existing skills and rely on past work experience. Take account of the level of disability.

- Keep the local community informed.

\section{Assessing impact}

This chapter discusses how to assess the impact of project activities on the client by observing the changes in each client's life. Recognizing and responding to such change is central to project management and planning. Similar methods may be used to assess the organization's progress towards its broader objectives.

Since impact assessment is fundamental to all field activities, the procedures described here will be of interest to staff at all levels.

\subsection{UNDERSTANDING IMPACT ASSESSMENT}

I don't want to hide my hands. I want to say, 'Look at my hands,' because they are a testimony to my experience, my history, showing that I have conquered every problem I had to overcome.

Yasuji Hirasawa, Japan All projects need to be efficient and effective. Broadly speaking, efficiency means making good use of resources, particularly funding, and effectiveness means achieving the desired impact. Assessing impact involves finding out what brought changes for the better and what brought changes for the worse (see Figure 4). This subsection will discuss how to decide which changes are important and whose values to apply in describing change.

SER sets out to change lives by reintegrating people into society and restoring their dignity and economic independence. Such changes are the main focus for impact assessment. It is the clients' own assessment of progress that carries most weight, especially in describing change for the better and change for the worse. Where objectives can be stated simply - for example, to increase the client's income-changes can be easily assessed. But where complex processes such as social integration are concerned, there may be no simple way to report progress. Two approaches are possible:

4. Identify the components of complex processes and use indicators, known as 'proxy measures', that demonstrate progress in each part.

5. Adopt one of the methods of Participatory Rural Appraisal (PRA) to identify progress towards objectives such as participation or empowerment (see 5.4).

Example. A group of indicators may be used to describe progress towards a complex objective such as integration. You might describe integration in terms of access to community resources, involvement in local festivals and social events, buying and selling in the market-place, location of housing, shared access to drinking water etc. Taken individually, none of these proxy measures is an adequate measure of integration, but considered together they give an overall picture of the level of integration. 
Groups of indicators can be used to describe all aspects of project activities and impact. In many situations, this will mean that you can avoid having to depend on the special skills involved in certain PRA methods (see 5.4 for examples of PRA methods that are simple to use and require little training). Subsection 5.2 now describes how one organization relies on a simple monitoring system using indicators.

\subsection{IDENTIFYING CHANGE}

The participatory approach is central to most development work and includes participatory involvement in monitoring. One of the larger NGOs involved in development work in Bangladesh has introduced a monitoring system that involves local people (clients) in assessing changes in their own lives. The resulting information is used to review progress throughout the organization. The focus is on the changes that take place under each of four headings:

1. Changes in people's lives

2. Changes in people's participation

3. Changes in the sustainability of their institutions and activities

4. Other changes

These changes are assessed by means of a selective reporting process involving three levels of staff: field workers, project managers and senior managers. Using a simple interview technique and addressing the four headings listed above, field staff encourage local people to describe any changes that have occurred over a 3-month reporting period. Field staff then identify what they consider to be the most significant changes to have taken place under each heading and submit reports to their project manager for local review. In turn, project managers select what they judge to have been the most significant changes across the project and forward the details to senior managers for overall review. At each stage the review process produces information about the impact of the work and what might be done to make it more effective.

A group of indicators is used for each heading. These include the following:

1. Changes in people's lives

Financial: saving money regularly, benefiting from loans, improved housing, new sources of income.

Health: using sanitary latrines, drinking clean water, eating balanced diet.

Personal: home and person neat and clean, sending children to school, acquiring literacy skills.

2. Changes in people's participation

Financial: participation in income-generating projects.

Social: active participation in groups, progress in solving problems, helping others to solve their problems.

Political: participating in local politics, addressing exploitation, injustices and rights issues.

3. Changes in the sustainability of institutions and activities

Developing the role of their groups.

Developing new skills and new sources of income among members.

Opening bank accounts for the group.

Saving group funds with a view to using them to support development activities.

Despite the potential for teething problems - such as missed deadlines and an unwillingness to report negative changes - the approach described here has much to offer 
projects involved in SER. Monitoring is closely integrated with routine fieldwork. There is a strong participatory element, with field staff reporting changes agreed with their clients. The information is filtered up through the organization so that staff and managers at each level are made aware of what is happening in the field.

\subsection{SELECTING INDICATORS}

I knew the training as caterers had been successful when two girls returned to the project compound. They politely refused my offer of work within the project. 'We are very sorry, sister, but we have already found work in the city. Please don't be offended.'

Contributor from Ethiopia Indicators are a way of assessing progress towards objectives. It is clear from the examples given in 5.2 that choosing indicators depends first of all upon common sense and experience. Brainstorming sessions with groups of staff or clients provide those with different expectations, perspectives and values the opportunity to participate in deciding which indicators are to be used and how each should be defined. There are two basic principles to be followed when selecting indicators:

- Principle 1. Begin by considering the project's objectives and choosing indicators that reflect progress. Identify proxy measures and groups of indicators where necessary (see 5.1).

- Principle 2. Wherever possible, adopt the words, phrases and values used by clients. Ask what changes the clients expect. Build upon their understanding and observations. Consult field staff and others.

Example: The comment from the accountant, 'It was successful because the loan was repaid on time and in full,' must take second place to the assessment of the loan recipient: 'We were able to repay the loan, but we didn't make enough profit to send our daughter to school.'

\section{Scoring systems}

Some indicators will require simple Absent/Present or Yes/No scoring. Others may use a series of graded scores, sometimes referred to as 'markers': for example, to reflect levels of increased understanding or responsiveness. The right scoring system will make it possible to describe simple changes and produce summary statistics in the form of percentages. For these to be useful you should pay special attention to the following:

- Each of the available scores (Absent or Present, Agree/Don't Know/Disagree, etc) must be clearly defined.

- For each indicator each score must be exclusive: that is, only one can apply at a time.

Where you are trying to measure progress towards a complex outcome (for example, participation), you may be unable to identify a satisfactory scoring system. PRA methods can produce the missing information or suggest alternative indicators and scoring systems (see 5.4).

\section{Performance}

The monitoring system can only produce useful information if data collection is regular and consistent. Ensure that:

- Indicators are based on data that is available when needed and that staff are trained in procedures to record and process it. 
- Data is collected using an agreed form or procedure so that standard reports can be produced on time.

Within the project cycle, it is important to review the performance of each indicator. From time to time it may be necessary to add new indicators or to stop using others. Remember that any changes you make will involve changes in data collection procedures and reporting in the field and will require further staff training.

\section{Basic requirements of an indicator}

To be of value, each indicator must meet certain basic requirements, as summarized below. These are described in detail in publications listed in 8 .

- Reliability. The words and phrases used to define an indicator or its scoring must be clearly understood. It is important that staff working independently produce the same scores when describing the same client or situation.

- Validity. Make sure that each indicator does in fact measure what it is intended to measure. Where similar indicators are used, check that changes in one match changes in the others.

- Simplicity. Don't confuse field staff by referring to several different factors within a single indicator (see Figure 16).

A meeting with a client identified a series of steps that could be used to report progress towards a new lifestyle: (1) isolated, begging for a living; (2) functioning links with family or project support; (3) good relationship with immediate neighbours; (4) good relationship with surrounding community; (5) accepted in the work force after skills training; (6) fully integrated into society.

The six stages involve a mixture of relationships, employment status and life-style, so assessing progress would be difficult: for example, changes in relationships will not automatically follow on from changes in economic status. The following steps show how functional indicators can be developed:

1. Consider separate indicators looking at (1) housing situation, (2) relationships and (3) employment.

2. Under housing situation, you might identify a series of markers such as (1) living alone, (2) living in community and dependent on begging, and (3) living in wider community.

3. You might describe changes in relationships using (1) no transactions with neighbours, (2) very occasional transactions with neighbours (marginal tolerance), (3) frequent transactions (tolerance), and (4) respected and fully functioning in local community (transactions would need to be defined).

4. Employment might be assessed in terms of (1) begging as only source of income, (2) some earned income but still begging, and (3) all income from employment or selfemployment.

Figure 16. Developing indicators. 
The listed publications also consider issues of subjectivity, relevance, sensitivity and specificity. The three indicators suggested should make it a straightforward task to assess and report changes. All three use the original terminology.

\section{Making a start with indicators}

If you are new to using indicators, do not start by introducing them throughout the project. Instead, begin by identifying a small number of indicators that can be used in clearly defined and limited situations. This will allow you to learn about the processes involved, and later you will be able to extend the practice.

In practice, indicators of economic status are the easiest to identify and use. Alternatively, you could examine the indicators of psychological, social and economic change listed in Figure 17 and further develop them with field staff. Figure 16 may be used as a training exercise in developing indicators.

\subsection{QUALITATIVE ENQUIRY}

It is important to understand the difference between quantitative and qualitative enquiry. Quantitative methods rely on making measurements against a set scale-for example, measuring income, age or education level—whereas qualitative methods are not limited by measurement or by statistical procedures.

Example of a quantitative method: Using a survey questionnaire that expects responses in

\section{Indicators of psychological status}

- Self-confidence: for example, the client's dependent on high, medium or low levels of intervention and support from the project.

- Self-acceptance, as reflected in wound care, regularity in MDT, awareness of need to avoid further impairment or disability.

- $\quad$ Capacity to manage a crisis, overcome problems.

Indicators of social status

- Access to drinking water and other community resources.

- Involved in normal buying and selling transactions; able to handle other transactions with community.

- Participation in community activities such as funerals, marriages, rituals, social gatherings, etc.

Indicators of economic status

- Employment status: for example, number of days employed during year, changes in actual income. Income and purchasing power. Increase in savings.

- Housing location and status. Resettlement. Move from rented to purchased property.

- Possession of assets. Better clothing. Ownership of household items. Involvement in buying and selling transactions, especially food.

Figure 17. Examples of indicators from the field. 
a standard form-for example, Agree or Disagree-is a quantitative method, because it defines and limits the answers that can be given to each question.

Example of a qualitative method: Asking open questions in an unstructured interview places no restriction on the questions that can be asked or on the responses that can be given, so this is a qualitative method.

Qualitative methods are 'open', in the sense that they can be used to collect new information and develop new ideas. By contrast, quantitative methods are relatively 'closed' since they allow only limited types of response. They tend to be used to describe an individual using existing ideas and terms.

The best-known qualitative methods are those used in Participatory Rural Appraisal, the procedures commonly used in development projects to build understanding shared with, and owned by, the local people themselves. PRA methods include interviews, observation and many other informal activities. The formality of the standard questionnaire favoured by many health programmes contrasts strongly with the openness that is central to many PRA methods (Figure 18).

\section{Which methods should I use?}

The interview technique used in the monitoring system described in 5.2 is one PRA method that does not require a high level of expertise. Example Two below describes another method that can be used with limited training; to identify other PRA methods refer to publications such as those listed in 8 that describe the quantitative methods and the circumstances in which they might be used. You should avoid a situation where the use of quantitative methods will generate large amounts of text that cannot be adequately analysed. Instead, identify a small number of manageable priority situations where quantitative methods may be used.

There is great value in using a succession of quantitative and qualitative methods, developing your earlier findings at each step (see Example 1, below).

\section{Qualitative methods in SER}

Qualitative methods are preferable in SER, for two important reasons:

1. Since they are not restricted by existing systems of measurement, they can be used to collect a wide range of information and to build understanding of complex situations and processes.

1. Sit down, listen, watch and learn: do not dominate, interview or interrupt.

2. Have an open agenda, allow improvisation and react to the opportunities that arise. Be flexible.

3. Unlearn. Ask for information and advice. Be open to discarding preconceptions. Base judgements on the information presented.

4. Hand over the pencil/chalk/stick. Facilitate. Start the process and then step back, listen and observe without interrupting.

5. Relax. Do not rush. Take time. Enjoy things with people.

6. Embrace error: be positive about mistakes -- recognize, share and learn from them.

7. Respect individuals. Rule 1: Be nice to people. Rule 2: Repeat rule 1. Rule 3: Repeat rule 2.

Based on Principles for assessment by Robert Chambers

Figure 18. The qualitative approach to learning. 
2. They can be used to provide the detailed information needed to identify indicators suitable for impact assessment, especially where sensitive issues such as gender, income and debt are concerned.

In each of the following examples, the information obtained from the field would have been written down and summarized in a report. Such reports describe underlying values, knowledge or processes that might result in changes to project priorities and plans.

\section{Example 1}

This example, based on a case study in Moris and Copestake, shows the wealth of information you can obtain if you find the right person to talk to.

We decided to conduct some interviews to validate the results of an earlier survey. An old woman asked me if, now that my questions were finished, she could tell me what she knew. She proceeded to give me twenty minutes of detailed information going far beyond the scope of the original survey. She certainly gave every impression of knowing a great deal, and was acknowledged locally as an authority in her subject.

Here the qualitative method-interviews - built on the information gathered through the earlier quantitative method-the survey. The woman interviewed provided a richness of information that went far beyond the simple answers to the survey questionnaire. All that was required was a simple interview technique and a willingness to listen.

\section{Example 2}

People who receive loans are often unwilling to reveal the profit they have made. This makes assessing the effectiveness of a loan scheme difficult. An approach based on comparisons can be effective.

I visited a group meeting where each of the women present had received a loan. I asked each to write her name on a piece of paper and then as a group to sort the pieces of paper into an order that matched the financial gain from their loans. A few minutes of animated discussion followed as the slips of paper were ordered and reordered. Finally there was agreement. I asked what those identified with the most gain had in common and how they differed from those with least. For half an hour the women poured out information about the effectiveness of the loans they had received, why some had benefited more than others and what would be done differently next time. Though I still did not know exactly how much profit had been made, I went away from the meeting with a clear understanding of why some women benefited more than others and what needed to be done to make the loan programme more effective.

The method described here depends on making comparisons and is known as 'Ranking'. Since it is less threatening than direct questions about profit and income, it produced information that answered the interviewer's questions about the loans scheme. The whole process is controlled by the initial question. This need not be restricted to the subject of money and can extend to questions of social or environmental change. You simply ensure that responses can be sorted in some way. Asking less specific questions requires group members to rely on their own understanding or definitions. 


\section{Understanding impact assessment}

- Impact assessment provides information about the effectiveness of a project: in other words, about quality rather than quantity.

- Indicators may be used to describe progress towards simple objectives.

- Groups of indicators (proxy measures) are used to describe progress towards more complex objectives.

- PRA methods may be needed to provide information that cannot be gathered by other means.

\section{Defining an indicator}

- Start from your project's objectives.

- Give priority to the words, phrases and viewpoint of the people most directly affected.

- Identify underlying concepts and the related proxy measures.

- Check reliability and validity.

- Define scoring systems.

- Identify data sources, methods and a schedule for data collection.

\section{Case studies and discussion material}

The case studies included in the full published Guidelines show how current projects have responded to local needs and opportunities. The discussion points are intended to encourage further analysis as readers draw comparisons with their own experience. This experience can be shared with people who do not have the language skills to read these guidelines: translating the stories and discussion material into the local context and the local language will elicit useful information about the understanding of field staff and their attitudes towards the work. Alternatively, the material may be used for training purposes.

The case studies are drawn from field experience and describe real situations. They raise questions about how decisions were made, how situations were handled and what results were achieved. Not all the answers are given; indeed, the projects themselves may still be looking for better ways to work. The persistence of some loose ends is intended to challenge the reader and stimulate analysis. The discussion questions are designed to extend that process and highlight the issues common to many projects.

\section{Getting started}

This chapter in the full publication summarizes the Guidelines by giving recommendations for action in response to four real-life scenarios. Each consists of a brief statement of context, some recommended reading and suggested points for action.

1. Introducing SER alongside a control and treatment programme

2. Linking project activities with national (government) programmes, NGOs and others involved in CBR

3. Addressing the causes of stigma

4. Starting impact assessment 


\section{References, resources and resource centres}

The Guidelines identifies the resource organizations and training centres listed here. There is also a reading list of more than 30 publications.

The following publishers and organizations produce materials relevant to SER.

- Healthlink Worldwide (formerly AHRTAG) is committed to strengthening primary health care and community-based rehabilitation in the South; Farringdon Point, 29-35 Farringdon Road, London EC1M 3JB, UK (e-mail info@healthlink.org.uk, Web site http://www.healthlink.org.uk).

- ILEP/TALMILEP publishes teaching and learning materials on leprosy; 234 Blythe Road, London W14 0HJ, UK.

- Teaching-aids at Low Cost, PO Box 49, St Albans, Hertfordshire AL1 4AX, UK.

- TLM International (Partners magazine for paramedical workers in leprosy).

- Intermediate Technology Publications Ltd, 103-105 Southampton Row, London WC1B $4 \mathrm{HH}, \mathrm{UK}$.

- Action Aid India (quarterly newsletter Disability News); Web site http://www/ actionaidindia.com/

- Oxfam Publishing, 274 Banbury Road, Oxford OX2 7DZ, UK.

- Tearfund (Footsteps, a quarterly publication on health and related development issues); 100 Church Road, Teddington, Middx TW11 8QE, UK.

- World Health Organisation Publications, 1211 Geneva 27, Switzerland.

- Social Science and Leprosy Network, a Web-based discussion group; to join the group, e-mail Jeanette.Hyland@utas.edu.au

- The Institute of Child Health, CBR Resource Centre, London (Web site http:/www. ich.ucl.ac.uk/library/cbr.htm).

- World Neighbours (periodic magazine In Action).

- INFOLEP

Centres offering training courses in SER or related subjects include the following:

- INF/Release, Nepal, c/o Mr Siegfried Beecken, SER Co-ordinator, INF Release Project, Partnership for Rehabilitation, PO Box 28, Pokhara, Nepal.

- (e-mail pfr@inf.wlink.com.np)

- GLRA, India, c/o Mr Srinivasan, Co-ordinator, GLRA, 4 Gajapathy Street, Shenoynagar, Chennai, 600 030, South India. (e-mail glra@md2.vsnl.net.in)

- DBLM, PO Box 3, Nilphamari, Bangladesh

- St Francis Leprosy Centre, Buluba, PO Box 1059, Jinja, Uganda

- Action Aid India. Web site http://www/actionaidindia.com/

- COMBRA, PO Box 9744, Kampala, Uganda

- Marie Adelaide Leprosy Centre, PO Box 8666, Karachi 74400, Pakistan

The following organizations involved in advocacy and their representatives are also identified:

- Dr PK Gopal, President, International Relations, IDEA, 58 Selvam Nagar, PO Box No 912, Collectorate PO, Erode, 638 011, India (e-mail: ideaind@vsnl.com).

- Ms Anwei Law, International Project Co-ordinator, IDEA, PO Box 133, Oak Hill, WV 25901, USA. (email: ideausa@inetone.net) 
- The International Leprosy Union is a federation of some national agencies directly providing field services in leprosy. Address: International Leprosy Union, Gurutrayi Building, 1779-1784, Sadashiv Peth, Pune 411 030, India

- National organizations for people with disabilities exist in Japan, Ethiopia, Brazil, Nigeria and elsewhere. Contact details are available from IDEA.

The following individuals participated in the preparation of the Guidelines. Many are still involved in the field.

\section{Africa}

Sr Senkenesh G Mariam, Medhen Social Centre, PO Box 70435, Addis Ababa, Ethiopia (e-mail contact via GLRA of fice below).

Mr Motbainer Abera, GLRA, PO Box 5033, Addis Ababa, Ethiopia (e-mail glra@telecom. net.et).

Catherine Benbow, ALERT, PO Box 165, Addis Ababa, Ethiopia (e-mail ahri@telecom.net.et). Christiane Averbeck, GLRA, PO Box 3017, Kampala, Uganda (e-mail glra@ starcom.co.ug). Ulrike Hanlon, formerly SER Co-ordinator for GLRA in Tanzania, PO Box 17, Frühlingstr 45, 97222 Rimpur, Germany (e-mail hodihodi@t-online.de). (GLRA Tanzania email: glratz@raha.com)

Papa Moctar Kandji, GLRA, PO Box 8262, Dakar-Yoff, Senegal (e-mail dahw@sonatel. senet.net).

Dr Magdy Garas, Social Consultant, and Dr Youssef Aziz , Head of Leprosy Project, Caritas Egypt, 24 Rue Saad Zaghloul, Alexandria, Egypt (e-mail caritas@alexnet.com.eg).

\section{Europe}

Dr Sunil Deepak, Medical Adviser, AIFO, 4-6 Via Borselli, 40135 Bologna, Italy (e-mail aifo@iperbole.bologna.it).

Dr Ji Baohong, Association Francaise Raoul Follereau, BP No 79, 75722 Paris, France.

Mr Ernst Hisch, SER Consultant, and Dr Jurgen König, Director, GLRA,

Mariannhillstrasse 1c, 97074 Würzburg, Germany (e-mail dahwd@geod.geonet.de).

June Nash, Technical Support, TLMI, 80 Windmill Road, Brentford, Middx TW8 0QH, UK (e-mail junen@tlmint.org)

Douglas Soutar, Head of Programmes, LEPRA UK, Fairfax House, Causton Road, Colchester, Essex CO1 1PU (e-mail doug_soutar@lepra.org.uk).

Dr Johan Velema, Evaluation and Monitoring Service, TLMI, PO Box 902, 7301 BD Apeldoorn, Netherlands (e-mail Velema@ems.tlmi.nl).

Professor Cairns Smith (Chair of ILEP Medico-Social Commission), Dept of Public Health, University of Aberdeen, Foresterhill, Aberdeen, Scotland, UK (e-mail w.c.s.smith@abdn. ac.uk).

Asia

Mr Antony Swamy, Managing Director, Worth Trust (Workshop for Rehabilitation and Training of the Handicapped), 48 New Thiruvalam Road, Katpadi B-632 007, Tamil Nadu, India. 
Mr Srinivasan, Social Worker and Co-ordinator, GLRA, 4 Gajapathy Street, Shenoynagar, Chennai, 600 030, South India (e-mail glra@md2.vsnl.net.in).

Dr Jal Mehta, Poona District Leprosy Committee, 35 Manisha Terrace, 2nd Floor, 2-A, Moledina Road, Pune, 411 001, Maharashtra, India.

Mr G Isaak, Manager, Icelandic Children Aid Training Centre, M. G. R. Colony, Malenaduvankarai, Anna Nagar, Madras 600 040, South India (e-mail glra@md2.vsnl.net.in).

Mr KDV Prasad, Project Superintendent, PVTC, The Leprosy Mission, Chelluru, Vizianagaram, 535005, A. P., India.

Dr Cornelius Walter, TLM, CNU Bhavan, 16 pandit pant Marg, New Delhi 110 001, India. Dr P K Gopal, President, IDEA India, PO Box 912, Collectorate, Erode, 638011 Tamil Nadu, India (e-mail ideaind@vsnl.com).

Mr Siegfried Beecken, SER Co-ordinator, INF Release Project, Partnership for Rehabilitation, PO Box 28, Pokhara, Nepal (e-mail pfr@inf.wlink.com.np).

Mr Bashir Vincent, Social Welfare Officer, and Dr Thomas Chiang, MAC, PO Box 8666, Saddar Karachi 74400, Pakistan (e-mail malcps@khi.compol.com).

Lorenzo Pierdomenico, Rehabilitation Department, AIFO-Vietnam, Bach Mai University Hospital, 3 Giai Phong Road, Hanoi, Vietnam (e-mail vietcbr@netnam.org.vn)

Dr Nuurshanty Andi Sapada, CBR Programme, PO Box 1463, Ujung Pandang 90014, South Sulawesi, Indonesia.

\section{South America}

Mr Peter Seidel, Ayuda Alemana a los Enformes de Lepra, Apartado Aéreo 86817, Santafé de Bogotá, Colombia (e-mail dahwayu@colomsat.net.co).

Dr Carlos Wiens, Hospital Mennonite KM 81, CdC 166, Asunción, Paraguay.

\section{ILEP staff}

Mary Tamplin and Sarah Lacey, ILEP Co-ordinating Bureau, 234 Blythe Road, London, W14 0HJ, UK (e-mail mtamplin@ilep.org.uk, slacey@ilep.org.uk)

Research and editing

Peter Nicholls, Public Health Dept, University of Aberdeen. Contact address: 46 Famham Road, Guildford, Surrey GU2 5LS, UK (e-mail PGNicholls@compuserve.com).

\section{Acknowledgements}

We are grateful to everyone who has contributed to the preparation of these guidelines, commented on the early drafts or participated in the Würzburg workshop in June 1999. Their contributions have resulted in a document that will be an important tool in organizing services for people affected by leprosy.

We would also like to express our thanks to the organizations that have provided funding and to the German Leprosy Relief Association for its guidance during the preparation of the guidelines. 
Principle Author

Peter Nicholls, Social Researcher and Statistician, University of Aberdeen

\section{Funding}

Aide aux Lépreux Emmäus-Suisse

Amici di Raoul Follereau, Italy

American Leprosy Mission

Association Française Raoul Follereau

British Leprosy Relief Association

Damien Foundation, Belgium

Fondation Luxembourgeoise Raoul Follereau

German Leprosy Relief Association

Netherlands Leprosy Relief Association

Sanatorio San Francisco de Borja, Spain

Sasakawa Memorial Health Foundation, Japan

The Leprosy Mission International 